\title{
HOSPITAL WASTE MANAGEMENT PRACTICES: EXPLANATION FROM MEDICAL PERSONNEL
}

\author{
Suriati Deraman ${ }^{1,}$, Lee Khai Loon ${ }^{2}$, and Puteri Fadzline Muhamad Tamyez ${ }^{2}$ \\ ${ }^{1}$ Faculty of Busines, DRB Hicom University of Automotive Malaysia, 26600 Pahang, Malaysia. \\ ${ }^{2}$ Faculty of Industrial Management, Universiti Malaysia Pahang, 26600 Pahang, Malaysia.
}

\begin{abstract}
Today, the healthcare industry has grown in importance as the number of hospitals has increased in response to the increased number of patients. This signifies that the world will be faced with more critical issues regarding hospital waste due to environmental impact. Current research fails to provide managers with a behavioural view on how to reduce waste in their organisations. Thus, this study explores the current hospital waste practices in hospitals in order to gain a better knowledge of recycling factor behaviour among medical personnel and the impacts of recycling hospital waste. To address the issues in this study, hospital managers were interviewed in a semi-structured interview. The result showed that respondents are willing to recycle hospitals due to factors such as government support, top management involvement through providing training, awareness, knowledge, facilities and incentives. This study will contribute to both body of knowledge and practice among hospital managers.
\end{abstract}

\author{
ARTICLE HISTORY \\ Received: $4-5-2021$ \\ Revised: 3-6-2021 \\ Accepted: 25-8-2021 \\ KEYWORDS \\ Hospital waste \\ Healthcare waste \\ Clinical waste \\ Biomedical waste \\ Financial impact \\ Environment impact
}

\section{INTRODUCTION}

Normally, recycling waste is a synonym for domestic waste or household waste, agriculture waste, construction waste, and food waste. How about hospital waste? Hospital waste contains different components of waste from hospitals, nursing homes, medical research facilities, clinics, and medical shops and, it differs in character and composition (Manzoor \& Sharma, 2019). Currently, hospital waste is divided into two categories, which are contaminated items and non-contaminated items.

Despite the fact that hospital, waste is managed contaminated biodegradable and non-biodegradable waste, fumes, and plastic contribute to pollution of land, air, and water (Khobragade, 2019). Therefore, as hospital managers, they are responsible of managing the waste to reduce pollution. From this perspective, the enablers for managers in implementing hospital waste recycling require investigation. The gap in terms of recycling behaviour among managers is important. This study will ultimately provide recommendations to stakeholders, and the government on how to improve the current hospital waste management.

According to Mekonnen, Geremaw, and Asefa (2020), more than half (57.4 percent) of the total hospital, waste produced in the hospital was general or non-risk healthcare waste, whereas the remaining 42.25 percent was hazardous healthcare waste. Therefore, recycling has become an alternative to reducing hospital waste, as it saves natural resources, saves electricity, reduces disposal costs, reduces toxic air and water pollution, saves money, and creates jobs (Asuamah, Kumi, \& Kwarteng, 2012).

Recycling hospital waste has attracted several hospitals to examine recycling or donating leftovers that are still accessible in developing countries such as Indonesia, Mexico, and Singapore (Halder \& Singh, 2018). Recycling is not only about reducing waste for the environment, but at the same time, it is also about waste management practices that can help to improve organisational performance systematically and effectively, particularly in the healthcare sector (Roslan, Habidin, Zainudin, Norazlan, \& Abdul Hadji, 2014). This study will contribute to both the body of knowledge and the practice among hospital managers.

\section{LITERATURE REVIEW}

Most theories are applied to measure individual capabilities and motivation, with limited reference to context and social factors. Davis, Campbell, Hildon, Hobbs, and Michie (2015) mentioned 82 theories used by researchers to measure human behaviour. The Theory of Planned Behaviour (TPB) was employed in this study because it is involved with the antecedents of recycling intention behaviour and is used widely to understand a range of environmentally responsible behaviour such as recycling (Alzahrani, Mahmud, Ramayah, Alfarraj, \& Alalwan, 2017; Lai, 2017).

Many studies used TPB to examine behaviour related to the adoption of product or service (F. Khan, Ahmed, \& Najmi, 2019; Lizin, Van Dael, \& Van Passel, 2017; Pivetti et al., 2020; Razali, Daud, Weng-Wai, \& Anthony Jiram, 2020; Sohrab Hossain et al., 2013; Strydom, 2018). This theory enabled them to discover determinant factors that can influence 
individual behavioural intentions in the adoption of the process. Managers, on behalf of management decision-makers, play a key role in implementing the new process in their organisation.

However, other variables identified in TPB that appear to have an essential role in recycling behaviour are not limited to these variables in TPB (attitude, subjective norms, and plan behaviour management). (Strydom, 2018). Many researchers proposed variables for their studies as extended variables such as facilities, government rule, awareness, knowledge, situation factors, motivation, management involvement, and other variables (Anwar et al., 2020; Arli et al., 2020; Iyer \& Kashyap, 2007; Jain, Singhal, Jain, \& Bhaskar, 2020; Kassai, Glais, Grenet, Cornu, \& Nguyen, 2018; Muniandy \& Anuar, 2020; Shan, Ang, \& Yang, 2020).

\section{METHODOLOGY}

A qualitative research approach was chosen for threereasons: 1) To identify the current practices of hospital waste recycling. 2) To examine the depth of understanding of recycling factor behaviour among managers. 3) To observe the impacts of hospital waste recycling from the perspective of medical personnel. This method allows the researcher to record not only verbal responses, but also observe any facial or bodily expressions (Bryman \& Bell, 2015). The data was collected through a total of 13 individual interviews.

The interview was conducted both in person and over the phone. The interview questions and data collection process were designed according to Campion, Palmer, and Campion (1997). The data collection process included an explanation and a recording that was subject to participant agreement and notification of anonymity. The selection of respondents required medical personnel with more than 3 three years of experience in the healthcare industry. This is important to ensure that respondents understand the items used and the process involved in recycling practices.

Three open-ended questions were used to guide discussions regarding the implementation of hospital waste recycling. The first question asked was about the status of recycling practices in Malaysian hospitals. The second question was, what are the factors that encourage medical personnel to implement hospital waste recycling? And the last question was, what are the impacts of recycling hospital waste? Each interview took about 10-15 minutes on average. The interview ended once the data had reached saturation. Each interview was transcribed within days. Researchers classified the detected elements of factor recycling using an open coding technique in this study.

As a result, thematic analysis was performed using Excell data analysis. In this approach, the transcripts' contents were categorized and labels were assigned to the emerging themes (categories). For ease of data analysis and synthesis, however, the data analytical procedure was informed by Rahman (2016) recommendations, which included data management (for example, data preparation, data labeling, and data itemizing/sorting), abstraction, and interpretation.

\section{RESULTS AND DISCUSSIONS}

\section{Current Status of Hospital Waste Recycling}

The analysis on the status of recycling hospital waste showed that 13/13 respondents mentioned that there was no implementation on this waste. Respondent \#5 and \#6 mentioned that to reduce disposal cost on hospital waste, the items such as hand sanitizer and hand rub were reused, which required them to collect from the ward and refill the liquid before returning to use. "Most of them are disposable. Cannot be recycled" and respondent \#13 said far as practical: although the item is not affected by the patient's body, but if we use it, we will continue to throw it away because we do not want any other infection... maybe from our own hands, right?".

However, respondent \#8 mentioned the situation at their workplace: "I agree that we have a lot.. like me as a head service of pharmacy.. indeed we have bottles... medicine bottles that do not contaminate, they do not contaminate even. The patient's body does not come in contact with the patient's body fluids so it is not contaminated".

According to WHO (2018), around 85 percent of the total volume of waste produced by healthcare operations is general, non-hazardous waste. A study from Gitipour, Pour and Firouzbakht (2017) found that, 38.35 percent (1.31 $\mathrm{kg} /$ day/bed) of hospital waste was contaminated waste, 57.85 percent $(1.99 \mathrm{~kg} /$ day/bed $)$ was non-infected waste, and 3.75 percent $(0.13 \mathrm{~kg} /$ day/bed $)$ was pharmaceutical and chemical waste.

\section{Factors Encouraging Hospital Waste Recycling Among Medical Personnel}

Top management involvement is one important factor for strategic management, the role of top managers in business success is central. In specific, the impact of the involvement of top management in project and portfolio performance (Hermano \& Martín-Cruz, 2016). The results show that institutional, process-based, and relational governance is favourably affected by top management support (Zhen, Xie, \& Dong, 2021).

Respondents \#8, \#9, and \#3 stated: "One I think, understanding from the top management, we have to have cooperation from them.. from there we can.. Then I think the importance is top management" Respondent \#6 mentioned: "So, we will get the support from our superiors, if we don't have a problem doing it. Aside from that, perhaps in terms of surrounding factors as well".

The study suggested, that management provide facilities such as bins of various colors and fitting yellow bags for infectious solid waste, black suit bins or domestic bags for solid waste, white plastic bags or medicinal and chemical waste bins and a safety box for sharp infectious waste should be required for proper handling of hospital waste (Gitipour et al., 2017). In addition, facilities in these countries also lack an adequate segregation, processing, safe storage, transport, 
and recycling of waste (B. A. Khan, Cheng, Khan, \& Ahmed, 2019). Respondent \#2 stated: “The hospital has no facilities to recycle hospital waste and whether we have to sort waste into plastic, glass, and paper, as seen on recycling bins or at common disposal sites. But there aren't any at the hospital." and this respondent also said: "I have no initiative to recycle. Because if I did, I wouldn't know where to send the waste as there are no facilities to help differentiate recyclable items from non-recyclable items. If you ask me whether I'll do it, I'd say no." Other answers about facilities in recycling hospital waste, according to respondent \#12, mentioned that:" If that happens, I'm still not sure whether it's possible because our workload in the ward is a lot. We barely have time as we have a lot of responsibilities in the ward. I don't think we have time to recycle. If the item is labeled as recyclable, then we'll recycle it. If it can't, it'll be disposed of as clinical waste.".

Another significant foactor is the government support. The implementation of recycling materials required knowledge of desirable practices to raise the level of cooperation later (Almasi et al., 2019). The best indicator of support for drinking recycled water in our logistic regression model was applicable knowledge (Glick, Goldfarb, Heiger-Bernays, \& Kriner, 2019). Many studies have shown that knowledge is a significant driver of recycling intention (Emy Ezura, Jing Foo, Zainab, \& Nur Asma, 2016; Sulaiman, Chan, \& Ong, 2019).

Respondent \#2 suggested: "Doctors or managers should be aware of the importance of recycled materials from hospital waste, and the fact that these items may turn out to be reusable. But, I don't know anything about it. So, it'll be great if there are any institutions or individuals who can explain it to the doctors and managers. So, the main factor is knowledge about recycling. Tell us about the benefits of recycling and what do we or other people gain from it? Second, we must instill awareness of recycling in ourselves. What are the impacts and the effects of hospital waste on the surrounding environment and future generations? And we are currently unaware of the situation. Perhaps it's because we believe it's a little nonsense." Respondent \#3 also agreed by stating: "Yes, for example from the environmental government or the municipal government" to support hospital waste recycling.

Multiple factors found to affect environmentally conscious actions, it has been shown that public perception of environmental issues is highly significant (Arli et al., 2020). Awareness refers to the proof of philosophy, knowledge, and abilities gained from both experience and schooling. If they have more awareness about recycling, a person is more likely to practice recycling behaviour (Schultz, Oskamp, \& Mainieri, 1995).

\section{Impacts of Hospital Waste Recycling}

Hospital waste recycling practices clearly can reduce waste and cost for the hospital when all respondents agreed that recycling can reduce waste and cost. Respondent \#1 suggested: "From the production, less production, less pollution, can reduce production and be able to take care of our environment" and respondent \#10 mentioned: "Recycling can reduce our waste disposal in terms of hospital costs, we do not add. Because of disposable disposal of waste we have to pay for the disposal of the waste... so if there is a lot of the waste disposal .. our hospital can recycle something that we can save cost to the hospital". Respondent \#13 stated: "Recycling waste is very good, it will reduce waste especially plastic and glass parts to our environment, any kind, whether ordinary waste or hospital waste will return the impact to the environment."

Similar findings were found in other studies. Other studies also mentioned that through the implementation of waste recycling at the organisation can and directly reduce disposal cost (Asuamah et al., 2012). The data also revealed that all respondents claimed that the cost for hospital waste disposal is high. They also mentioned that producing large amounts of waste means that they need to spend a lot of money and incur a lot of hospital expenses. Other studies also concluded that in minimizing the cost of hospital waste, an adequate waste generation reporting and proper segregation could open up vast possibilities for HCW minimization, recycling, and safe care and disposal initiatives (Baaki, Baharun, Ali, \& Jaafar, 2018).

The study findings provided the factors that encourage the manager to recycle hospital waste at the workplace. Overall, all participants stated that there was no procedure, policy, own initiative for recycling hospital waste at their organisation. Other respondents also mentioned the need for training, awareness, and management support to implement a new process for hospital waste. The current practices only involve domestic waste. The questions about factors that encourage them to recycle stated that high cost, facilities, knowledge, awareness, incentives, government action, reduced operational cost, and environmental impact are all elements that drive them to recycle.

This input has been discussed in other studies. Besides an understanding of recycling intention factors, this study looks into the current problem of handling hospital waste at the organisation. They need equipment to remove it and separate it with a different bin for easier recycling segregation. The recycling process is not only in their organisation; third parties, such as collectors, also need to improve in ensuring the safety of themselves and others when handling hospital waste, especially if it falls into the low-risk category.

\section{CONCLUSION}

This study investigated medical personnel's perspective on hospital waste recycling at their workplace. This is important because manager behaviour toward hospital waste recycling plays an important role in the successful implementation of hospital waste recycling. The present study is conducted to find the key that encourages factors to recycle hospital waste. Lack of funding impedes implementation and enforcement actions, and sometimes a lack of 
community involvement and participation is a major constraint on improving the standard of waste management services, according to a previous study.

The findings of the study both have theoretical and practical implications. Hospital waste can now be recycled through proper handling and procedure within the good facilities at the company. Other than that, knowledge and awareness are seen as an important element in ensuring the implementation of hospital waste recycling. Participants also highlighted that other elements, such as cost for disposal, top management involvement, and incentives are important to encourage hospital staff to recycle their waste from their activities.

As a result of these findings, hospital managers can encourage medical personnel to recycle hospital waste and improve the current waste disposal procedure. The success of recycling hospital waste is inextricably linked to the organisation's financial, economic, and environmental performance. Therefore, policymakers and decision-makers need to take consideration to upgrade current hospital waste management in parallel with countries. Others claim that this study opens opportunities to develop new businesses and jobs on hospital waste recyling industries, which can then be sold as non-contaminated hospital waste.

However, this study have some limitations, such as minimal number of respondents. Sekaran (2003) proposed that only small samples of people, groups, or events should be chosen. Due to time, energy, and expense restrictions, a comprehensive analysis of all components with a large sample size was not possible.

\section{DECLARATION OF COMPETING INTEREST}

The authors declare that they have no known competing financial interest or personal relationship that could have influenced the work reported in this paper.

\section{ACKNOWLEDGEMENT}

The authors would like to thank all the participants of this study who took part in the individual interviews. Not to be forgotten are UMP lecturers in giving ideas, assistance and motivation to complete this study.

\section{REFERENCES}

Almasi, A., Mohammadi, M., Azizi, A., Berizi, Z., Shamsi, K., Shahbazi, A., \& Mosavi, S. A. (2019). Assessing the knowledge, attitude and practice of the kermanshahi women towards reducing, recycling and reusing of municipal solid waste. Resources, Conservation and Recycling. https://doi.org/10.1016/j.resconrec.2018.10.017

Alzahrani, A. I., Mahmud, I., Ramayah, T., Alfarraj, O., \& Alalwan, N. (2017). Extending the theory of planned behavior (TPB) to explain online game playing among Malaysian undergraduate students. Telematics and Informatics, 34(4), 239-251. https://doi.org/10.1016/j.tele.2016.07.001

Anwar, N., Nik Mahmood, N. H., Yusliza, M. Y., Ramayah, T., Noor Faezah, J., \& Khalid, W. (2020). Green Human Resource Management for organisational citizenship behaviour towards the environment and environmental performance on a university campus. Journal of Cleaner Production, 256, 120401. https://doi.org/10.1016/j.jclepro.2020.120401

Arli, D., Badejo, A., Carlini, J., France, C., Jebarajakirthy, C., Knox, K., ... Wright, O. (2020). Predicting intention to recycle on the basis of the theory of planned behaviour. International Journal of Nonprofit and Voluntary Sector Marketing, 25(2). https://doi.org/10.1002/nvsm.1653

Asuamah, S. Y., Kumi, E., \& Kwarteng, E. (2012). Attitude Toward Recycling and Waste Management: a Survey of Marketing Students in Sunyani Polytechnic, Ghana. Advances in Arts, Social Sciences and Education Research, 2(5), 158-167. Retrieved from http://www.ejournal.sedinst.com

Baaki, T. K., Baharun, M. R., Ali, A. S., \& Jaafar, M. hasni. (2018). Exploring sustainable healthcare waste management implementation in teaching hospitals in Malaysia. LKMU Research Online.

Bryman, A., \& Bell, E. (2015). Business Research Methods. Methods. 4th edition.

Campion, M. A., Palmer, D. K., \& Campion, J. E. (1997). A review of structure in the selection interview. Personnel Psychology. https://doi.org/10.1111/j.1744-6570.1997.tb00709.x

Davis, R., Campbell, R., Hildon, Z., Hobbs, L., \& Michie, S. (2015). Theories of behaviour and behaviour change across the social and behavioural sciences: a scoping review. Health Psychology Review, 9(3), 323-344. https://doi.org/10.1080/17437199.2014.941722

Emy Ezura, A. J., Jing Foo, Y., Zainab, A. A., \& Nur Asma, Y. (2016). Recycling Behaviour Among Malaysian Tertiary Students. Journal of Technology and Operations Management 11.

Gitipour, S., Pour, F. A., \& Firouzbakht, S. (2017). Assessment of medical waste in Tehran province hospitals. Journal of Environmental Studies, 42(4), 709-718.

Glick, D. M., Goldfarb, J. L., Heiger-Bernays, W., \& Kriner, D. L. (2019). Public knowledge, contaminant concerns, and support for recycled Water in the United States. Resources, Conservation and Recycling. https://doi.org/10.1016/j.resconrec.2019.104419

Halder, P., \& Singh, H. (2018). Predictors of recycling intentions among the youth: A developing country perspective. Recycling, 3(3), 1-16. https://doi.org/10.3390/recycling3030038

Hermano, V., \& Martín-Cruz, N. (2016). The role of top management involvement in firms performing projects: A 
dynamic capabilities approach. Journal of Business Research. https://doi.org/10.1016/j.jbusres.2016.01.041

Iyer, E. S., \& Kashyap, R. K. (2007). Consumer recycling: role of incentives, information, and social class. Journal of Consumer Behaviour. https://doi.org/10.1002/cb.206

Jain, S., Singhal, S., Jain, N. K., \& Bhaskar, K. (2020). Construction and demolition waste recycling: Investigating the role of theory of planned behavior, institutional pressures and environmental consciousness. Journal of Cleaner Production. https://doi.org/10.1016/j.jclepro.2020.121405

Kassai, B., Glais, F., Grenet, G., Cornu, C., \& Nguyen, K. A. (2018). Reducing waste in pediatric clinical research. Therapie, 73(2), 181-184. https://doi.org/10.1016/j.therap.2017.11.013

Khan, B. A., Cheng, L., Khan, A. A., \& Ahmed, H. (2019). Healthcare waste management in Asian developing countries: A mini review. Waste Management and Research, 37(9), 863-875. https://doi.org/10.1177/0734242X19857470

Khan, F., Ahmed, W., \& Najmi, A. (2019). Understanding consumers' behavior intentions towards dealing with the plastic waste: Perspective of a developing country. Resources, Conservation and Recycling. https://doi.org/10.1016/j.resconrec.2018.11.020

Khobragade, D. S. (2019). Health Care Waste: Avoiding Hazards to Living and Non Living Environment by Efficient Management. Fortune Journal of Health Sciences, 02(02), 14-29. https://doi.org/10.26502/fjhs007

Lai, P. (2017). the Literature Review of Technology Adoption Models and Theories for the Novelty Technology. Journal of Information Systems and Technology Management, 14(1), 21-38. https://doi.org/10.4301/s180717752017000100002

Lizin, S., Van Dael, M., \& Van Passel, S. (2017). Battery pack recycling: Behaviour change interventions derived from an integrative theory of planned behaviour study. Resources, Conservation and Recycling. https://doi.org/10.1016/j.resconrec.2017.02.003

Manzoor, J., \& Sharma, M. (2019). Impact of Biomedical Waste on Environment and Human Health. Environmental Claims Journal, 31(4), 311-334. https://doi.org/10.1080/10406026.2019.1619265

Mekonnen, B., Geremaw, M., \& Asefa, A. (2020). Assessment of healthcare waste generation rate and management practice in Assessment of healthcare waste generation rate and management practice in the case of Mizan-Tepi Tepi University Teaching Hospital Southwest, Ethiopia. Intern Res J of Med Scie, 8(1), 1-8.

Muniandy, G., \& Anuar, M. M. (2020). Determinants of academicians recycling behaviour. Management Science Letters, 10(7), 1597-1606. https://doi.org/10.5267/j.msl.2019.12.007

Pivetti, M., Melotti, G., Vespa, M., Cappabianca, F., Troilo, F., \& Placentino, M. P. (2020). Predicting recycling in Southern Italy: An exploratory study. Resources, Conservation and Recycling. https://doi.org/10.1016/j.resconrec.2020.104727

Rahman, M. S. (2016). The Advantages and Disadvantages of Using Qualitative and Quantitative Approaches and Methods in Language "Testing and Assessment" Research: A Literature Review. Journal of Education and Learning, 6(1), 102. https://doi.org/10.5539/jel.v6n1p102

Razali, F., Daud, D., Weng-Wai, C., \& Anthony Jiram, W. R. (2020). Waste separation at source behaviour among Malaysian households: The Theory of Planned Behaviour with moral norm. Journal of Cleaner Production. https://doi.org/10.1016/j.jclepro.2020.122025

Roslan, M. H., Habidin, N. F., Zainudin, M. Z., Norazlan, A. N. I., \& Abdul Hadji, N. S. (2014). Waste Management Practices and Organization Performance in Malaysian Healthcare Industries. Journal of Applied Science And Research, 2(JANUARY), 14-22.

Schultz, P. W., Oskamp, S., \& Mainieri, T. (1995). Who recycles and when? A review of personal and situational factors. Journal of Environmental Psychology. https://doi.org/10.1016/0272-4944(95)90019-5

Sekaran, U. (2003). Research Methods For Business.

Shan, X., Ang, W. L., \& Yang, E. H. (2020). Mobile app-aided risks, attitudes, norms, abilities and self-regulation (RANAS) approach for recycling behavioral change in Singapore. Resources, Conservation and Recycling, 162(July), 105049. https://doi.org/10.1016/j.resconrec.2020.105049

Sohrab Hossain, M., Ab Rahman, N. N. N., Balakrishnan, V., Puvanesuaran, V. R., Zaidul Islam Sarker, M., \& Ab Kadir, M. O. (2013). Infectious risk assessment of unsafe handling practices and management of clinical solid waste. International Journal of Environmental Research and Public Health, 10(2), 556-567. https://doi.org/10.3390/ijerph10020556

Strydom, W. F. (2018). Applying the theory of planned behavior to recycling behavior in South Africa. Recycling, 3(3). https://doi.org/10.3390/recycling3030043

Sulaiman, N., Chan, S. W., \& Ong, Y. S. (2019). Factors influencing recycling intention among University students. International Journal of Innovative Technology and Exploring Engineering, 8(8), 336-340.

WHO. (2018). WHO | Health-care waste. Retrieved from http://www.who.int/mediacentre/factsheets/fs253/en/

Zhen, J., Xie, Z., \& Dong, K. (2021). Impact of IT governance mechanisms on organizational agility and the role of top management support and IT ambidexterity. International Journal of Accounting Information Systems, (xxxx), 100501. https://doi.org/10.1016/j.accinf.2021.100501. 


\section{AUTHORS' BIOGRAPHY}

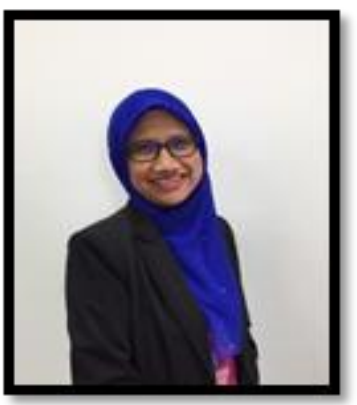

Suriati Deraman is a Supply Chain Management lecturer at DRB- HICOM University of Automotive Malaysia since August 2017. Previously, from 2008 to 2017, she worked in the healthcare industry as a Quality Officer and Procurement Officer. She is a certified professional scheduled waste from the Environment Institute of Malaysia since 2015.

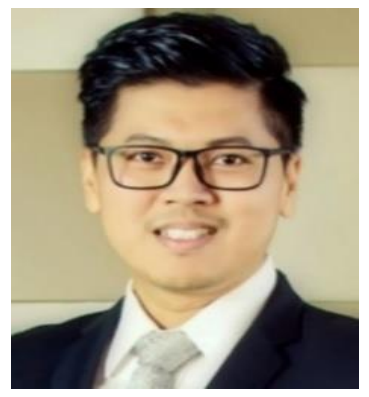

Ts. Dr. Lee Khai Loon is a Senior Lecturer and the Head of Program (Business Engineering) at Faculty of Industrial Management (FIM), Universiti Malaysia Pahang (UMP). He specialised in supply chain management, technology management, operation management, industrial engineering, and business management. He holds a Doctor of Philosophy (PhD) in Supply Chain Management and a bachelor's degree in technology management from the School of Technology Management and Logistics, Universiti Utara Malaysia. He has a long industrial experience in the fastmoving consumer goods (FMCG), fashion, food and beverage, and manufacturing industries. He started his first academic career in 2015. He has received numerous academic, research, and product innovation awards. He is a chartered member of The Chartered Institute of Logistics and Transport (CMILT) Malaysia and UK, a Professional Technologist in Malaysia Board of Technologists (MBOT), an HRDPF Certified Trainer (TTT), and a Certified Microsoft Innovative Educator.

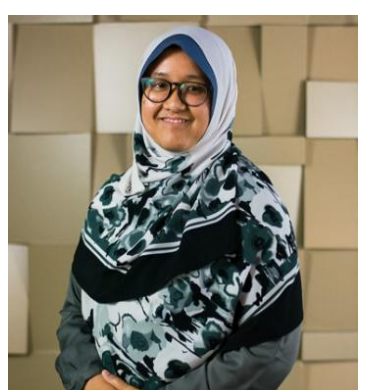

Assoc. Prof. Dr. Puteri Fadzline bt Muhamad Tamyez is currently the Deputy Dean of Research and Postgraduate Studies in Faculty of Industrial Management, Universiti Malaysia Pahang. She graduated from Universiti Technology MARA, Shah Alam, with a PhD in Business Management and from Universiti Sains Malaysia, Penang with BSc and MSc degrees in Bioresources under the School of Industrial Technology. Prior to joining Universiti Malaysia Pahang, she had accumulated industrial experiences in the furniture and wood flooring industries for 4 years. Her research interests are Business Management, Innovation Management, Product Management, and Research Methodology. She can be reached at the Faculty of Industrial Management, Universiti Malaysia Pahang, Lebuhraya Tun Abdul Razak, 25300, Kuantan, Pahang, via email at fadzline@ump.edu.my or by phone at +09-549 2445. 